\title{
Research Upon the Relativity Between Digital Media and Tourism
}

\author{
Wei Feng ${ }^{(凶)}$ and Peng Wang \\ Shandong College of Tourism and Hospitality, 3556, East Jingshi Road, Jinan, Shandong, China \\ 13964076217@163.com
}

\begin{abstract}
This thesis originates from the authors both as tourism educators and multimedia professionals loving nature and travelling. In this information era, digital media has turned out to be the most common medium of social life with the content of communication shifting from text-centered ones to interactive multimedia forms of images and videos. Mingling in the Nature, human society and the virtual world, digital media is developing rapidly with dazzling new concepts and technologies such as new media, We Media, and media convergence. Digital media has its unique tool in creation which is further fortified by computer and network technology at the aim of comprehensive artistic interaction. Hence a variety of VR, AR, and $\mathrm{H} 5$ are being widely used. The nature of tourism activities is the interaction between people and nature. The development of society and the improvement of people's living standards have gradually increased the proportion of tourism activities in people's daily lives. Tourists have a strong dependence on information. Whether it is communication or expression, the traditional tourism industry cannot meet the needs of the public. The combination of the fastest growing digital media and the broadest travel culture will inevitably produce unique and fascinating products. In view of the characteristics of digital media and modern tourism, the relationship between them is mutually reinforcing and inseparable. The promotion, promotion and implementation of tourism are inseparable from digital media. Every step of social development is driven by innovation and demands. Digital media and tourism are entering into the era of individuality, both complimenting, incorporating, and improving for mutual success and representing a vigorous and promising prospect for us.
\end{abstract}

Keywords: Digital media $\cdot$ Tourism $\cdot$ Short video

\section{Introduction}

The latest data of the Statistical Report on the Development of the Internet in China issued by CNNIC is shown in Fig. 1. As of June 2019, Chinese mobile Internet access traffic consumption reached 55.39 billion GB, a year-on-year increase of $107.3 \%$. In particular, the major video platforms further segmented content categories, focusing on IP (Intellectual Property). Form a coordinated entertainment content ecosystem in areas such as video content and music, literature, games, and e-commerce [1]. 


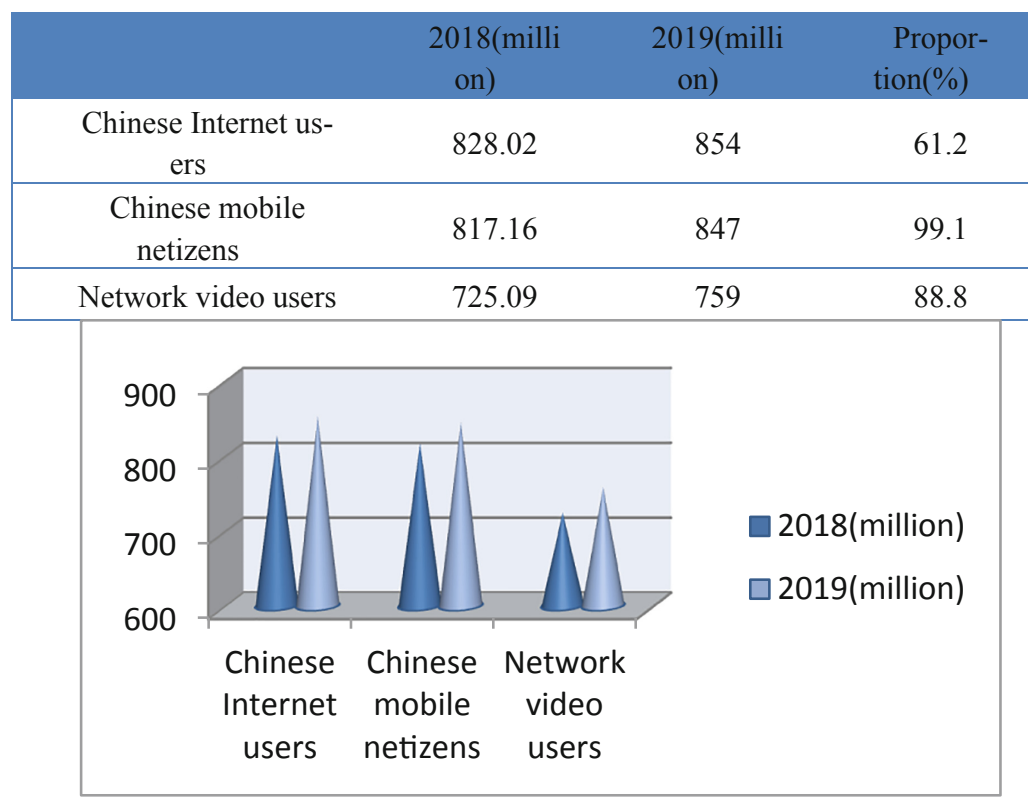

Fig. 1. The 44th Statistical Report on Internet Development in China (Source: Author)

At the same time, the data of Q2 Global Digital Report 2019 is shown in Fig. 2. As of early April 2019, there were more than 5.1 billion mobile phone users worldwide, smartphones accounted for more than two-thirds of all devices, and $98 \%$ of global social media users (over 3.4 billion people) accessed social platforms via mobile devices. GlobalWebIndex data shows that nearly half of Internet users aged 16 to 24 use voice features, while less than $30 \%$ of users aged 45 and older use voice [2].

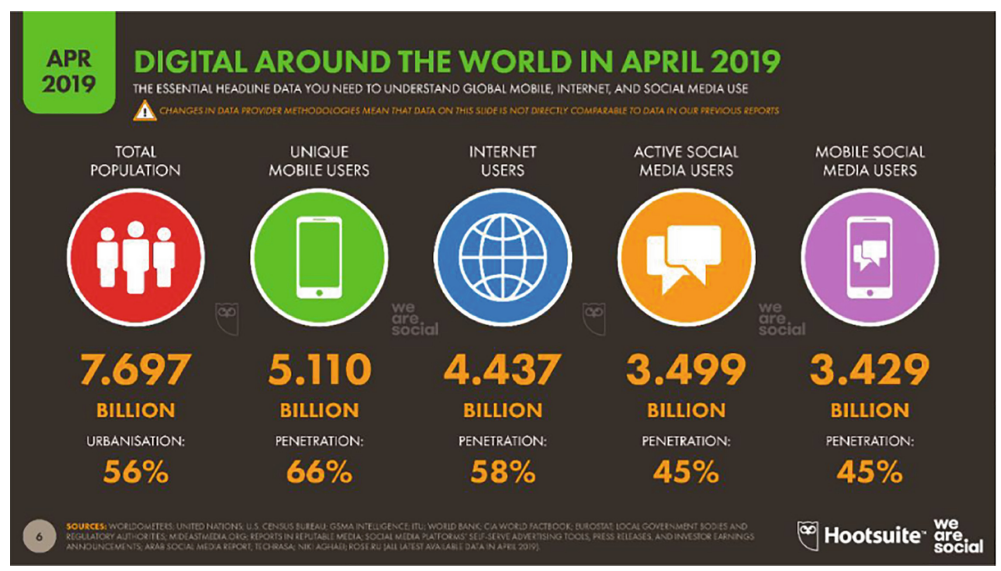

Fig. 2. Q2 Global Digital Report 2019 (Source: Baidu search) 


\section{Digital Media Overview}

Today's society is in the era of the great development of the Internet. Traditional media is gradually changing to digital media. Compared with the past traditional media era, this era has changed a lot. As binary expressions composed of 0 and 1 are more stable and reliable, it is inevitable that digital media will gradually replace traditional media and become mainstream media. The interactive nature of digital media has led audiences to actively select and publish information. The audience is not only passively waiting for the content to be distributed, but as long as they are willing, everyone can use digital media to become the main body of the communication. At the same time, benefiting from cloud computing and big data technologies, diverse and personalized content can be more accurately pushed to the audience. In recent years, China's digital social platforms have developed rapidly. New concepts and technologies have emerged endlessly, and various expressions are overwhelming, such as new media, media convergence, and self-media. There are also many new communication methods, such as WeChat public account, Weibo, TikTok, WeChat applets (compared with foreign countries, such as YouTube, Facebook, etc.); VR, AR, H5 and other various application technologies emerge endlessly.

\subsection{Definition}

Compared to traditional media, digital media is a newer concept and form. It is sometimes called new media. "It is a form of communication that uses digital technology and network technology to provide users with information and entertainment services through channels such as the Internet, wireless communication networks, satellites, and terminals such as computers, mobile phones, and digital televisions. Strictly speaking, new media should be called digital media" [3]. Traditional media usually refers to newspapers, magazines, televisions, and broadcasts. Among them, newspapers and magazines belong to paper media, and television and radio belong to the analog domain; All paper media information can be re-encoded according to computer coding standards, and the analog signals can be converted into digital signals through the process of sampling, quantization and encoding (as shown in Fig. 3), which is very convenient for storage, editing, carrying, sharing and spread.

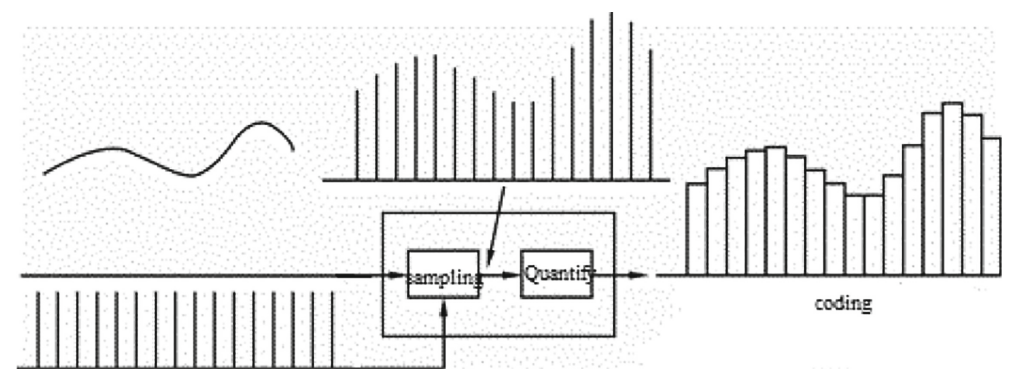

Fig. 3. The process of sampling, quantization, and encoding (Source: Baidu search)

"In fact, digital media is different from new media. Digital media is digitally defined, so the connotation and expansion of new media is more abundant." [4]. From the etymological point of view, the word "New Media" was proposed by P. Goldmark, the 
director of the Columbia Radio and Television Network Technology Institute in 1967, and gradually expanded to the whole world [5]. It is iterative and a developing concept. For example, over time, broadcasting is new media relative to newspapers, and television is new media relative to broadcasting. Since the Internet was officially used as the official definition of the United Nations in 1998, the Internet has become a new medium relative to television. Modern new media has digital characteristics. It can be said that digital media is a new media at this stage.

In summary, the new media can be regarded as digital media.

\subsection{Features}

\section{1) Integrated/Diversity}

Digital media can be used to express a variety of information such as text, graphics, audio and video through different combinations of 0 and 1 . It has integration and diversity (integration of technology, diversity of expression methods, and diversity of communication channels). Because of digital media includes diversified media elements, making the information richer and more vivid, it is gradually replacing the traditional media form with the highest user rate.

\section{2) Interactivity}

From keyboards to mice, from touch screens to speech recognition, the way humans interact with digital devices is becoming more humane, tending to simpler and faster shortcuts, and the fragmented time of humans is occupied by digital devices. Interactive performance is much easier to implement in the digital domain than in the analog domain, so interactivity is a basic characteristic of digital media.

\section{3) Real-time}

Audience feedback has changed from limited time and limited places in the past to interactive expressions anytime, anywhere. This kind of instant interaction brought by convenient operation greatly enhances the audience's sense of participation and immersion, and makes the communication content easier to spread. The inefficient one-way transmission of traditional media has evolved into the high-efficiency two-way transmission of digital media, and the audience has begun to actively select and disseminate information. This feature can obviously improve the efficiency of information dissemination.

\section{4) Personalization}

Innovative digital media has entered the era of personalization. Digital media can use its strength to combine different audiences' preferences, performance pictures, text, sound, image and other combined information to achieve the purpose of personalized communication. The effectiveness of accurate dissemination based on big data depends entirely on whether the information for different audiences has personalized tags, which is also a typical feature that distinguishes it from ordinary mass communication.

In the future, it will be intelligent. It will be a multi-point to multi-point communication method for everyone (to quote from "Introduction to New Media in the Intelligent Age") Compared with single-point-to-multipoint transmission in traditional media, there 
are more methods, more flexible directions, and easier content diffusion. Of course, it is more prone to a lot of invalid information, and you should pay special attention to it.

It is an indisputable fact that the paper carrier that has been circulating for thousands of years, the CD that has been in use for 40 years, and the mobile phone that has been in use for 20 years have been spiked by smartphones that have only appeared for 10 years. Digital media is not only a concept of technology, but also a new type of communication. Facts have proved that it affects the development of various fields deeply by affecting the behavior of the audience.

\subsection{Forms and Channels of Communication}

What is the first thing when modern people open their eyes every day? I believe that for many people, it is to pick up a mobile phone, which is an extension of online media. Whether it is a PC, a notebook, or a smart phone-type mobile terminal, digital media basically includes the following forms of communication: digital publishing, digital music, digital games, digital audio and video, etc.; The main communication channels are websites, video platforms and apps.

Digital media presents a strong social attribute on devices such as smartphones. Different regions have created many different social networking sites, video platforms and related apps. For example, China's Weibo, WeChat, short videos such as Tik Tok, and long videos such as Youku. And well-known WhatsApp, Facebook, Twitter, Instagram, YouTube, etc.

The ultimate purpose of technology is to serve people. It is the best choice to make digital media as the main communication carrier, combined with traditional media.

\section{The Essence of Tourism}

The essence of tourism is the interaction between man and nature.

\subsection{Historical Origin}

Human tourism activities originate from the migration of primitive people. The movement of people during migration is one of the most basic characteristics of tourism. However, the migration of primitive people is for survival needs, which is different from the tourism activities of modern society. With the increase of productivity and economic level, real tourism activities are gradually prevailing. There are lots of records from the Silk Road pioneered by Emperor Hanwu of China, to <The Travels of Marco Polo>, which was created in 1299, then from Zheng He's voyages to the west in the 15 th century Chinese Ming Dynasty (see Exotic Images on the right), to the Geographical Discovery era. Even in China, the opening day of "The Travels of Xu Xiake" was designated as China Tourism Day on May 19, 2011. There

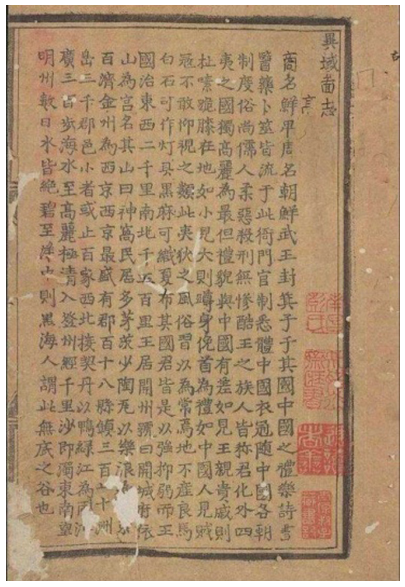


is an old saying in China: "It is better to travel ten thousand miles than to read ten thousand books." At this time, tourism activities were mainly economic exchanges and adventures.

\subsection{Development Status}

With the continuous progress of society and the improvement of the living standards of the masses, the world is relatively peaceful and stable, and people's pursuit of spiritual and cultural life is on the agenda. Tourism can relax your body and mind, broaden your horizons, and is ideal for leisure activities in your spare time. Therefore, the proportion of tourism activities in people's daily life has gradually increased and has become an important part of people's lives around the world. Tourism has also become one of the world's largest industries.

The "China Domestic Tourism Development Annual Report 2019" issued by the China Tourism Academy on September 21, 2019 predicts that the number of domestic tourists in China will reach 6.06 billion in 2019. Young people born after 90 years have become the backbone of tourism; According to the "2019 China Tourism Development Report" released on December 19, 2019, the number of domestic tourists, outbound tourists, and inbound tourists in China was 5.54 billion, 149.7 million, and 141.2 million. China's comprehensive tourism contribution ranks second in the world [6].

The "China Mobile Internet Development Report (2019)" mentioned that through the extensive expansion and application of smartphones and mobile Internet, the penetration rate of mobile tourism users has continued to increase, and the mobile terminal has become the most important sales channel for the tourism industry. At the same time, mobile tourism companies have deepened the offline development of tourist destinations, and companies in different fields have begun to move into mobile tourism. Online tourism has entered the era of mobile tourism, and mobile has become an important trend in the tourism industry.

The theme of World Tourism Day 2018 is “Digital Development of Tourism". China Tourism Research Institute and Google and Google jointly released the "2019 China Inbound Tourists' Behavior and Attitude Analysis Report", which believes that the right time, the right content and the right channels of information release are critical to improving the experience of inbound tourists [7].

\subsection{Development of Tourism Activities}

An effective tourism activity should have the following steps: Tourists obtain information, choose a destination, Reservation (including transportation arrangements, accommodation arrangements, food arrangements), entertainment and activities, sharing and evaluation, as shown in Table 1.

In the process of tourism activities, tourists and tourism attractions are the two most important elements to maintain the overall tourism activities. Only if there are differences and uniqueness can tourism resources become tourism attractions. 
Table 1. Tourism steps and realization channels (Source: Author)

\begin{tabular}{l|l|l|l|l|l}
\hline Step & $\begin{array}{l}\text { Access to } \\
\text { information }\end{array}$ & $\begin{array}{l}\text { Choose a } \\
\text { destination }\end{array}$ & Reservation & $\begin{array}{l}\text { Entertainment } \\
\text { and activities }\end{array}$ & $\begin{array}{l}\text { Sharing and } \\
\text { evaluation }\end{array}$ \\
\hline Content & $\begin{array}{l}\text { Check } \\
\text { website } \\
\text { attractions, } \\
\text { short videos, } \\
\text { brochures, } \\
\text { travel } \\
\text { agencies, } \\
\text { reviews, etc. }\end{array}$ & $\begin{array}{l}\text { Country/Area, } \\
\text { City, } \\
\text { Countryside }\end{array}$ & $\begin{array}{l}\text { Transportation, } \\
\text { Accommodation, } \\
\text { Food, Tickets }\end{array}$ & $\begin{array}{l}\text { Natural } \\
\text { Landscapes, } \\
\text { Historical } \\
\text { Monuments, } \\
\text { Museums, } \\
\text { Events }\end{array}$ & $\begin{array}{l}\text { Share travel } \\
\text { feelings, } \\
\text { experiences, } \\
\text { reviews }\end{array}$ \\
\hline $\begin{array}{l}\text { Channel } \\
\text { OTAs, social } \\
\text { networking } \\
\text { sites/apps, } \\
\text { short video } \\
\text { platforms, } \\
\text { travel } \\
\text { agencies, etc. }\end{array}$ & $\begin{array}{l}\text { Travel agency, } \\
\text { independent } \\
\text { travel, } \\
\text { customized } \\
\text { tour }\end{array}$ & $\begin{array}{l}\text { OTA, car rental } \\
\text { companies, } \\
\text { related websites, } \\
\text { etc. }\end{array}$ & $\begin{array}{l}\text { Scenic spots } \\
\text { and } \\
\text { surrounding } \\
\text { excursions, } \\
\text { using virtual } \\
\text { reality scenes }\end{array}$ & $\begin{array}{l}\text { OTA, social } \\
\text { networking } \\
\text { site/app, } \\
\text { short video } \\
\text { platform }\end{array}$ \\
\hline
\end{tabular}

\subsection{The Essence of Tourism}

The essence of tourism is the interaction between man and nature. The tourism industry is an industry resulting from information asymmetry. Tourists are very dependent on tourism information, so the essence of the tourism industry is the process of information interaction. As the famous anthropologist Daniel Miller pointed out, the virtual world and the real world are two equal spaces and should no longer be favored one more than another. People travelling online and offline are not learning how to use technology, but learning how to live better in these two spaces [8].

\section{The Relevance of Digital Media and Tourism}

Due to the above description of the nature of digital media and tourism, it can be seen that the relationship between digital media and tourism is inseparable and mutually reinforcing. The acquisition of tourism information, the display of tourism resources, the promotion of tourism destinations, and the development of tourism activities can be achieved using digital media; At the same time, the virtual world and the natural world are connected by people, and frequent interactions have created many new formats, new channels, new technologies, new methods, and new careers related to digital media, promoting the further development of digital media. Tourists often obtain cross-validation of tourism-related information through multiple channels, especially at the beginning of finding a destination. Digital tourism channels are indispensable at all stages of the entry and exit of tourists. At present, the main information acquisition channel is still the search engine. At the same time, tourism product comparison sites and video sites have grown significantly in importance over the past two years. 


\subsection{Digitalization of Tourism Resources}

The description of tourist attractions is particularly important during the preparation phase of tourism activities. The motivation of tourism mainly depends on how much tourists are interested in tourism attractions. No matter it is a humanistic landscape, natural landscape or a tourist commodity, the visual perception at first glance determines to a large extent whether tourists will initiate tourism activities.

In the past, text, brochures, and category pictures were the most commonly used means of describing tourism resources, which was single, flat, and poor visual impact; Taking advantage of digital media technology to produce a video trailer with a text commentary is much better, but it is more old-fashioned, boring, and cannot fully present the characteristics of the landscape. And a pure promo is not as accurate as a landscape picture processed with PS, or a fun short video. Digital media technology can achieve artificial sublimation of the natural environment. For example, the bird's-eye view of Daming Lake in Jinan and the world's Internet celebrity Li Ziqi (As shown in Fig. 4). Almost every video shot by Li Ziqi is only about $7 \mathrm{~min}$, one theme at a time. The entire communication in the video uses Chinese, but it has conquered the world with traditional Chinese food and crafts. By the end of January 2020, she has 8.12 million followers on YouTube, with a total of 1.02 billion videos played. The traditional Chinese cultural heritage and images of the ancient and idyllic life presented in the video are unforgettable. It can be seen that there are good expressions, scenes and content are more contagious than words and languages.
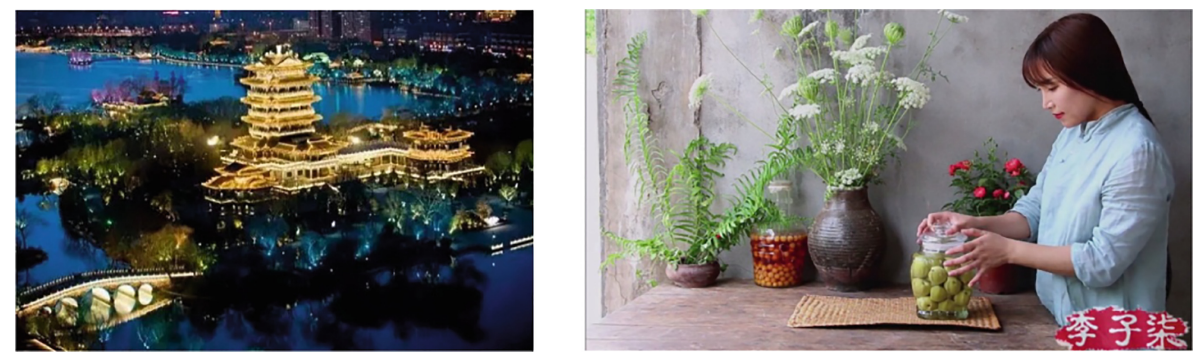

Fig. 4. Jinan Daming Lake and Internet celebrity, Li Ziqi (Source: Baidu search)

VR/AR and holographic projection are also very suitable technical means to display tourism resources. Use VR technology to turn typical tourism resources into virtual reality scenes and conduct 360-degree immersive experiences through the network, allowing tourists to visit without leaving the house; The introduction of scenic spots in the travel manual using AR technology effectively combines traditional media and digital media, so that tourists can get a richer understanding when they obtain travel information. In fact, the main problem that VR/AR technology can solve is unreachability, which is very suitable for tourism resource display. When tourists are inconvenient to travel, or tourism resources have disappeared or are difficult to reach for various reasons, virtual reality scenes are the most suitable means of display. For example, the reconstruction of the Great Water Law in Beijing's Yuanmingyuan, digital museums with various themes, 
intangible cultural heritage (Chinese traditional folk activities), virtual reality scenes used for environmental reconstruction in research trips promoted by China. Universal Studios in the United States also uses VR technology to reproduce some movie scenes for tourists to participate in the experience, which is very popular. Of course, VR technology also has many shortcomings, such as taking up memory, making it difficult to fully display, and dizziness. If the scenic area is divided into small scenes for presentation, this problem can be effectively avoided. With the increase of network speed and technological progress, these problems will be gradually solved.

\subsection{Tourism Destination Promotion Channels}

The development of the times and the advancement of technology have created more new channels for digital publicity and promotion. Tourism, as the world's largest industry, is also participating. The theme of World Tourism Day 2018 is "Digital Tourism Development". Tourism propaganda, promotion, and implementation are inseparable from digital media. The out-going nature of tourism has also become a good carrier for digital media development.

\section{1) Short Video}

With the advent of $4 \mathrm{G}$ and $5 \mathrm{G}$, content is lighter, time is more fragmented, and highimmersion short videos are increasingly entering the daily life of the public. The short video promotes a new platform for tourism destination image dissemination, which will become an important means of mobile tourism marketing.

Take Tik Tok as an example, entertainment is subdivided into 14 categories. In addition to pets, games, beauties, music, life skills, and food, it also includes 8 mainstream dimensions of tourism, funny, paragraph, dance, little brother, cute baby, fashion, and creativity. KOL marketing started in the era of Weibo and has now entered the era of social video. The reason why social video can be the most important channel for KOL marketing is because of its strong interaction. The methods of exchanging experiences, sharing recommendations, and answering questions accurately reach the target consumer groups. KOL fans are very sticky and have a high conversion rate, because each KOL has its own unique charm and label, which will attract the same type of users. Therefore, brands choose KOL for advertising, which helps brand information reach users more accurately.

As Maggie Wang, AdMaster's vice president of business strategy and innovation said: "This is the era of content, consumer demand is becoming more and more diverse, and the core of social marketing-content requirements are becoming higher and higher. $\mathrm{KOL}$ is the content producer. A good KOL, in addition to being influential and having a good content creation ability, also needs to suit the brand's tone and category needs [9]."

In the mainstream dimension of tourism, in addition to the use of content production for short-term video platform for tourism destination marketing, nowadays, as free travel becomes more and more common, affected travel agencies can also use this platform to divert travel agency personnel. The difference between a star KOL and an ordinary $\mathrm{KOL}$ is that the audience is willing to paying for the former because they like the star 
itself, and the positioning is a free "sales consultant", which requires high levels of "professionalism". The short video platform is no longer satisfied with simply "short" and "fast", and the lengthening of the time (from $15 \mathrm{~s}$ to $1 \mathrm{~min}$ ) is also trying to guide users away from instant gratification and enter the field of depth and connotation. The tour guides are very familiar with the situation of the attractions and marketing strategies. They have experience and professional advantages. They can completely switch to the short video platform. By making a series of interesting short videos related to attractions, they will become online travel destination KOLs, potentially promoting the area. KOL's Key Opinion Leader (KOL) formation path is shown in Fig. 5.

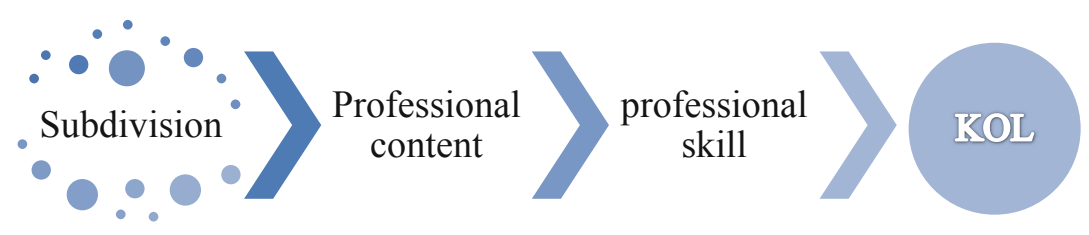

Fig. 5. KOL formation (Source: Author)

Professional guides continue to promote tourism resources through free short videos to form potential customer groups. When people with common interests come together, it is easy to direct purchase behavior. Take KOC (Key Opinion Consumer) as the starting point, transition to the tail KOL, and then grow to the head KOL. Use the influence to open a VLOGGER account at the same time. As shown in Fig. 6.
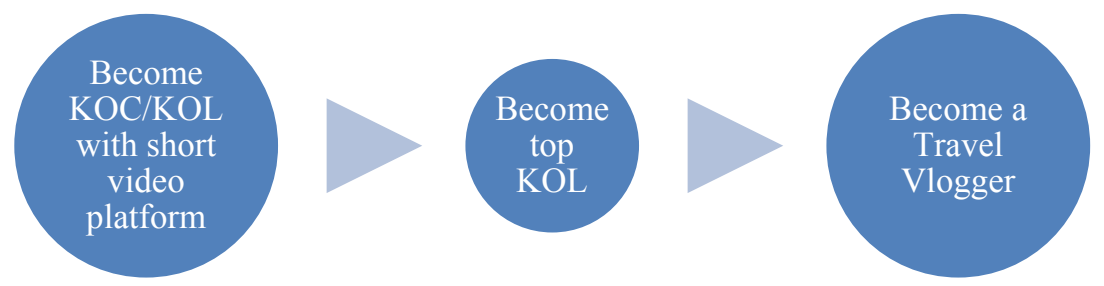

Fig. 6. The growth path of online travel professionals (Source: Author)

According to CaasData, the development direction of short videos must be a combination of short videos and PGC (Professionally-generated Content). The former quickly grabs the hearts of the people, and the latter is responsible for the capacity and density of the content. Both experiences are important. The tour guides can use their professional advantages to enter the PGC field of tourism short videos [10]. A platform's PGC and UGC can have intersections. As users of the platform, they also contribute content with a certain level and quality in a professional capacity. 
CaasData from conventional short video platforms such as Tik Tok, Kwai, etc. found that pure tourism content is not receiving much attention. It has a lot to do with insufficient participation and insufficiently attractive content. The most popular and fastest-growing kinds are mostly funny and gourmet. With the development of social economy and culture, the public's willingness to travel will become stronger and more diversified, and the corresponding demand for good products and services will also increase. We can combine travel destination content with the most popular and fastest growing categories of short video platforms. Taking Tik Tok2019's fastest-growing three categories of cars, food and beauty as examples, it can correspond to self-driving in tourism, specialty foods in scenic areas and beauty-carrying attractions. Of course, it also puts forward higher requirements for diversified quality of KOL.

In addition, Bilibili had brilliant precedents for game and travel themes. For example, Might and Magic, released in 1986 and produced by New World Computing (NWC); A single-player game released in 1990 and produced by Japan's KOEI Glorious Corporation (KT Corporation)-the Great Sailing Age, players claim that "the world map is in my heart"; They are all popular games with the background of traveling around the world and the vast universe as popular.

\section{2) Social Platform}

Taking WeChat as an example, the data report from WeChat 2019 shows that as of January 2020, WeChat has 1.151 billion monthly active users. "Tencent 2019 Digital Life Report" shows: offline consumption has been fully digitized. Social, referral, and personalized purchases are advocated by users. The WeChat public platform has gathered more than 20 million public accounts, and the active peak period is $9 \mathrm{pm}$. Many public accounts have formed their own brands. Using the public account platform can make full use of a variety of digital media means to achieve content push, advertising marketing, etc. The public account is the same as traditional media in single-point to multipoint transmission, but the public account has an interactive function.

In addition, WeChat Mini Programs have been widely used. It can rely on the WeChat platform to be quickly acquired and disseminated like green software, with simple development and excellent user experience.

In response to the mobile Internet trend in the Chinese market, the second largest source country, Tourism New Zealand has formulated a strategic shift from PC to mobile. On November 7, 2019, the New Zealand Tourism Board released the "New Zealand Tourism Expert Training Program" developed on the WeChat platform at the 6th New Zealand Greater China Tourism Fair (as shown in Fig. 7). This small program is extremely social and shareable. As long as users complete 11 modules of learning through the small program and pass the online test, they can obtain the "New Zealand Travel Expert Bronze Medal". In this way, not only can you achieve professional and systematic knowledge of New Zealand's tourism destinations, promote New Zealand's tourism information, but also attract more young people to join New Zealand's customized tourism industry. Many other countries, such as the United Kingdom and Germany, have also used their small programs to develop their own national tourism expert programs, providing a way for tourism resource promotion and tourism enthusiasts to become professionals. 


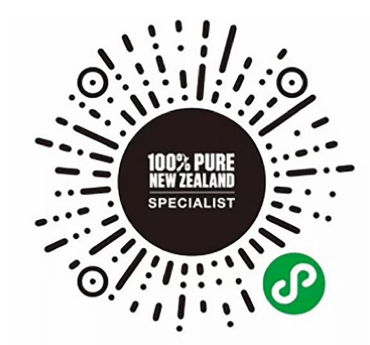

NEW ZEALAND SPECIALIST MINH - PROBRAM

Fig. 7. New Zealand travel expert mini program (Source: WeChat public account)

\subsection{Create Tourism IP and Develop New Tourism Products}

At present, the homogeneity competition in the tourism industry is becoming increasingly fierce. Problems such as a single form of tourism, weak interaction, backward marketing methods, and insufficient exploration and protection of existing tourism resources have restricted the development of many tourist attractions. Some badly managed scenic spots even face the danger of being eliminated by the market. At the same time, tourists are becoming more and more experienced and knowledgeable, and ordinary natural and human landscapes can no longer meet their needs. From the perspective of tourism enterprises, they need more diversified and attractive means of publicity and promotion and tourism attractions to influence the ideas of tourists, so as to get more tourists; From the perspective of tourists, they hope to get more convenient tourist information channels, richer tourism products, and more cost-effective tourism experiences. What is lacking in the era of national tourism is not the market nor the resources, but new products that meet the needs of different levels. Combining regional characteristics, dig deep cultural connotation, and use a variety of digital media methods, such as photography, PS, animation, short video, pixel painting, etc. Create interesting travel communication content and LOGO, create a new travel IP, create beauty in ordinary life, and use digital technology to reconstruct the traditional relationship network.

In recent years, many Internet celebrities have appeared in China, such as the intersection of Qingdao Yushan Road and University Road, which first appeared in the guide of tourism websites. Later, after many live webcasts, it became the most popular cultural attraction in Qingdao, and was called "the corner meets love" by many netizens; The Kuanhouli, which is in author's hometown of Jinan, became a must-visit place in Jinan through the Lian Yinshe's small video shot to fame of Tik Tok. These are new tourism products that have appeared in recent years. They are all interesting and suitable for the tastes of young people. They are highly sought after intangible spontaneous communication through the Internet.

\subsection{Carry Out Tourism Activities and Establish an Effective Supervision Mechanism}

OTA (Online Travel Agency) can be said to be an early platform for using digital media technology for tourism activities. Each OTA has the basic functions of booking hotels, 
transportation, and tickets; at the same time, it is full of pictures, videos, guides and various evaluations of tourist attractions. At present, the entire online travel industry has a stable user scale of about 240 million. For example, some common OTAs such as Ctrip, Qunar, Flying Pig, Tongcheng, etc. They have already segmented the market and have different characteristics. Business travellers often use Ctrip with a generous one-stop service; Students prefer "where to go", the interface is bright; Flying Pig users are mainly traveling abroad, [11] and the interface is simple and intuitive; The opening rate of Tongcheng app ranks first, and it has a lot to do with the intuitive interface. The differences in common people are closely related to their business themes and digital media design styles.

After the end of the May 1 tourism consumption season in 2019, online travel (OTA) has become the hardest hit area for consumer complaints. SaleCycle data shows that in 2019, the average online booking abandonment rate reached $90.74 \%$. Hot issues are mainly focused on 10 different aspects: default tying, overlord clauses, big data tricks acquaintances, order reversion, information leakage, false publicity, low price traps, price increases or no tickets after ordering, and order errors (wrong orders, missing orders, etc.) and travel accident compensation [12]. Travel is a life experience, with a particular focus on the quality of the experience. We should make full use of the platform's tourism monitoring and evaluation functions to improve tourism services, enhance strengths and avoid weaknesses, and re-awaken audiences' trust in the platform. Let digital media technology be a weapon in our hands, not a double-edged sword.

In early 2020, an epidemic led by 2019-nCoV broke out in parts of China. The vast majority of people chose to stay at home to avoid the attack of the virus, which severely damaged the original Spring Festival tourism market. This unexpected event also tested the market's resilience. During the period, short video views and game downloads surged. As we all know, tourism activities are activities that leave the place of residence for the purpose of sightseeing. When the path of movement is cut off, how to save the vitality of the tourism market in emergencies poses a severe test for us. OTA can open a dedicated virtual travel channel, with short videos, VR scenes, and travel experience mini-games as the main content, leading the audience to discover goals in their free time so that they can make a trip in the near future. The travel experience mini-game can be guided by the travel strategy of a popular tourist destination. The process of playing the game is the process of successfully completing a travel activity, so that the audience can also experience the travel process at home. It is believed that after this epidemic, the tourism market will usher in a new climax.

\section{Conclusion}

Today's cloud computing technology is relatively mature. At the same time, major websites and social platforms have abundant big data, but the mining of travel data is obviously not enough. Relying only on data analysis of high-frequency words and search focus to infer audience preferences and trends, such pushes can even mislead data collection, produce wrong media. The final goal of the media professionals is combine the attributes of digital media and tourism activities better, using digital media to make tourism attractions glow. Ultimately let audiences get the best life experience combined 
with virtual and real world, online and offline. Every development of society is driven by innovation and demand. Both digital media and tourism have entered the era of personalization. They are mutually reinforcing and inseparable, they achieve each other and promote each other, presenting us with a development prospect full of vitality and unlimited potential.

\section{References}

1. CNNIC: The 44th Statistical Report on Internet Development in China [EB/OL], 30 August 2019. http://www.cnnic.cn/hlwfzyj/hlwxzbg/hlwtjbg/201908/t20190830_70800.htm

2. 199IT:: We Are Social \& Hootsuite: Q2 Global Digital Report 2019 [EB/OL], 01 May 2019. http://www.199it.com/archives/870212.html

3. Huang, C., Qi, L., Wang, Q., et al.: Introduction to New Media. Beijing: Communication University of China Press, Beijing (2013)

4. Baike: Digital Media [EB/OL]. https://baike.baidu.com/item/\%E6\%95\%B0\%E5\%AD\%97\% E5\%AA\%92\%E4\%BD\%93/4295071?fr=aladdin

5. Chen, J.: Analysis of the definition and connotation of "new media". Ind. Sci. Forum 10(7), 28-29 (2011)

6. Useit: China Tourism Academy-2019 China Domestic Tourism Development Annual Report [EB/OL], 30 September 2019. https://www.useit.com.cn/thread-24846-1-1.html

7. Tourism Circle-China Tourism Academy: 2019 China Inbound Tourists Behavior and Attitude Analysis Report [EB/OL], 05 September 2019. https://www.dotour.cn/article/147414.html

8. IT: Tencent 2019 Ditigal Life Report [EB/OL], 23 May 2019. http://www.199it.com/archives/ 880232.html

9. SOHU: Under the three major trends of vertical, real and short video, KOL marketing requires new skills [EB/OL], 06 July 2017. http://www.sohu.com/a/146546998_292667

10. CAASDATA: <2019 Short Video KOL Annual Report > Heavy Release: After the explosion period, gradually shift to a stable growth period [EB/OL], 13 January 2020. https://mp.wei xin.qq.com/s/0O8O-fp-cVd5VEidTMU2Xg

11. Mob Research Institute: 2019 OTA Industry Insight Report (with download) [EB/OL], 15 August 2019. http://www.199it.com/archives/919967.html

12. People.com: Survey on Hot Issues in Online Tourism Consumer Rights Protection [EB/OL], 14 May 2019. http://finance.people.com.cn/n1/2019/0514/c1004-31083025.html 